Bond capacity of severely corroded bars with corroded stirrups

K. Zandi Hanjari, D. Coronelli and K. Lundgren

Published in Magazine of Concrete Research, see journal homepage http://www.icevirtuallibrary.com/content/journals

"Permission is granted by ICE Publishing to print one copy for personal use. Any other use of these PDF files is subject to reprint fees." 


\section{Bond capacity of severely corroded bars with corroded stirrups}

\section{Kamyab Zandi Hanjari}

Research Assistant, Department of Civil and Environmental Engineering, Structural Engineering, Concrete Structures, Chalmers University of Technology, Göteborg, Sweden

\section{Dario Coronelli}

Assistant Professor, Dipartimento di Ingegneria Strutturale, Politecnico di Milano, Milan, Italy

\section{Karin Lundgren}

Professor, Department of Civil and Environmental Engineering, Structural Engineering, Concrete Structures, Chalmers University of Technology, Göteborg, Sweden

Eccentric pull-out tests were carried out to study the influence of severe corrosion leading to extensive cover cracking, and the effect of corroded and non-corroded stirrups on the anchorage of deformed bars. The specimens were subjected to a low-rate electrochemical corrosion process for three time spans that caused a rebar weight loss up to approximately $20 \%$ in the main bars and $35 \%$ in the stirrups. Pull-out tests were then carried out in each specimen, on either the two corner bars or the middle bar, to measure the bond capacity. The effects of corrosion and the mechanical testing were simulated with non-linear finite-element analysis. The combination of tests and analyses gives a better understanding of the effect of high corrosion penetrations and the presence of corroded stirrups on failure modes. The presence of stirrups, corroded and non-corroded, was found to significantly change the behaviour of an anchorage region, namely the corrosion-induced crack pattern, the failure mode and the bond capacity.

\section{Notation}

c stress in the inclined compressive struts

$E_{\mathrm{c}} \quad$ elastic modulus of concrete

$E_{\mathrm{s}} \quad$ elastic modulus of steel

$F_{1}, F_{2} \quad$ yield functions

$f_{\text {cc,cube }} \quad$ concrete compressive strength with cube specimens

$f_{\text {cc,cylinder }}$ concrete compressive strength with cylinder specimen

$f_{\mathrm{ct}} \quad$ concrete tensile strength

$f_{\text {su }} \quad$ ultimate strength of reinforcement

$f_{\text {sy }} \quad$ yield strength of reinforcement

$G_{\mathrm{F}} \quad$ fracture energy

$r \quad$ bar radius

$s \quad$ free-end slip

$u \quad$ relative displacement

$x \quad$ corrosion penetration

$y \quad$ free increase of the bar radius due to corrosion

$\mu \quad$ coefficient of friction

$\sigma \quad$ traction

$\sigma_{\mathrm{n}} \quad$ splitting stress

$\sigma_{\mathrm{t}} \quad$ bond stress

$\tau_{\mathrm{b}} \quad$ average bond stress

$\tau_{\max } \quad$ average bond strength

$v_{\text {rs }} \quad$ volume rust/volume steel

\section{Introduction}

The anchorage capacity of deformed bars in concrete is strongly influenced by the actual confinement conditions. In general, confinement is a result of the surrounding concrete, stirrups and transverse pressure. Corrosion of reinforcement leads to volume expansion of the steel, which generates splitting stresses in the concrete; this influences the bond between the concrete and reinforcement. At a larger corrosion penetration, the splitting stresses may lead to cover cracking and, finally, spalling of the concrete cover. In an extreme situation, when cover spalling occurs, the resisting mechanism in the cross-section is altered; stirrups become the primary source of confinement, which results in residual anchorage capacity. Corrosion of stirrups not only reduces the stirrup area but also weakens the confinement provided by the concrete owing to extensive cover cracking. For a natural corrosive environment, in which both longitudinal and transverse reinforcements are corroded, anchorage and shear failure become more probable.

The effect of corrosion attacks on bond strength has been studied by several researchers (Almusallam et al., 1996; Cabrera and Ghoddoussi, 1992; Clark and Saifullah, 1993; Fib, 2000; Hussein et al., 2002; Lee et al., 2002; Saifullah and Clark, 1994). Earlier research by the authors has identified some of the uncertainties in the knowledge available today (Zandi Hanjari, 2008). A significant uncertainty is the remaining anchorage in structures with severely corroded reinforcement, especially where extensive cracking has taken place or the cover has spalled off. This has been investigated in a few studies. Regan and Kennedy Reid (2009) studied a similar situation by testing beams, cast without 
concrete cover, in which bars were either flush with the concrete surface or exposed to mid-barrel. A reduction of the bond strength of up to $90 \%$ was observed for the bars exposed to midbarrel; however, the swelling effect of rust and the effect of corroded stirrups were not taken into account. Tests carried out on highly corroded beams with over $20 \%$ bar weight loss have shown that relatively high residual load-carrying capacity was reached when corroded beams failed in bending (Azad et al., 2007; Zhang, 2008). However, the impact of severe corrosion on the anchorage capacity of deformed bars has not been widely studied.

The influence of corroded stirrups on structural performance has been investigated in very few studies; thus this can be claimed to be another uncertainty in current knowledge. Corrosion of the stirrups produces local and uniform section loss. This may lead to localised yielding, reduced ductility and, finally, complete fracture of stirrups at severely corroded locations. Shear and anchorage strength as well as deformation thereby may be significantly influenced (Higgins and Farrow III, 2006; Regan and Kennedy Reid, 2004).

This research contributes to the understanding of the anchorage behaviour of severely corroded bars. The combined effects of high corrosion penetrations and of corroding stirrups on the anchorage regions are experimentally and numerically investigated.

\section{Experimental programme}

Eccentric pull-out tests were carried out to investigate the anchorage capacity of a severely corroded bar. The location of the bar, middle or corner position, the amount of transverse reinforcement, and the corrosion level of longitudinal and transverse reinforcement were included in the study. The test programme is summarised in Table 1. Since a high scatter of results is usually expected in this type of test, 18 specimens were cast. Half of the total number of specimens was made without sodium chloride, while the rest were cast with $3 \%$ sodium chloride mixed into concrete to accelerate the corrosion process.
Details on the tests are given in Zandi Hanjari and Coronelli (2010).

The specimens were of three types with respect to the reinforcement arrangement and corrosion of main bars and stirrups:

(a) Type A: without stirrups, main bars were subjected to corrosion.

(b) Type B: with stirrups, only main bars were subjected to corrosion.

(c) Type C: with stirrups, main bars and stirrups were subjected to corrosion.

\section{Material}

Test specimens were cast with a concrete of grade C30/37 mixed in two batches: mix I with $3 \%$ sodium chloride and mix II without sodium chloride. The compressive and tensile strengths of the concrete were measured using $150 \mathrm{~mm}$ cube and $200 \times 100 \mathrm{~mm}$ cylinder specimens cast from the same concrete batches. All of the specimens were kept in a laboratory environment for 28 days, after which they were demoulded and kept in a curing room at $20^{\circ} \mathrm{C}$ and $50 \%$ relative humidity. The deformed hot-rolled bars used in the specimens were tested in tension. Concrete and steel properties are presented in Table 2.

\section{Test specimens}

The geometry of the eccentric pull-out specimens was similar to that used by Magnusson (2000), which had the shape of a beamend after inclined shear cracking; see Figure 1. The behaviour of the eccentric pull-out test shares some similarities and dissimilarities with a beam-end region. For example, similar to a beamend region, the inclined strut is carried both on the anchored bar and the support region. However, in the test specimens, the main bars were not in contact with the concrete over the support; see Figure 2. The effect of support pressure and the anchorage of the bar over the support are, therefore, not the same as at the end of a beam.

The specimens were cast with the main longitudinal reinforcement

\begin{tabular}{|c|c|c|c|c|c|c|}
\hline \multirow[t]{2}{*}{ Corrosion level } & \multirow{2}{*}{$\begin{array}{l}\text { Weight loss of } \\
\text { main bars: \% }\end{array}$} & \multirow{2}{*}{$\begin{array}{c}\text { Corrosion } \\
\text { cracking: mm }\end{array}$} & \multirow{2}{*}{$\begin{array}{l}\text { Position of } \\
\text { tested bar(s) }\end{array}$} & \multicolumn{3}{|c|}{ No. of specimens } \\
\hline & & & & Type A & Type B & Type C \\
\hline \multirow[t]{2}{*}{ Reference } & No corrosion & No cracks & Middle bar & 3 & 2 & - \\
\hline & & & Corner bars & 2 & 2 & - \\
\hline \multirow[t]{2}{*}{ Level 1} & $\sim 0-2$ & $<0.4$ & Middle bar & - & 1 & - \\
\hline & & & Corner bars & - & 1 & - \\
\hline \multirow[t]{2}{*}{ Level 2} & $\sim 2-10$ & $0 \cdot 4-1 \cdot 0$ & Middle bar & 1 & - & - \\
\hline & & & Corner bars & 1 & 1 & \\
\hline \multirow[t]{2}{*}{ Level 3} & $\sim 10-20$ & $>1$ & Middle bar & - & 1 & 1 \\
\hline & & & Corner bars & - & 1 & 1 \\
\hline
\end{tabular}




\begin{tabular}{|c|c|c|c|c|c|c|c|c|}
\hline \multirow[b]{2}{*}{ Mix } & \multicolumn{4}{|c|}{ Concrete } & \multicolumn{4}{|c|}{ Reinforcement } \\
\hline & $f_{\mathrm{cc}, \text { cube }}: \mathrm{MPa}$ & $f_{c c, c y l i n d e r:}: \mathrm{MPa}$ & $f_{\mathrm{ct}}: \mathrm{MPa}$ & $G_{F} *: N / m$ & $E_{\mathrm{C}}{ }^{*}: \mathrm{GPa}$ & $f_{\mathrm{sy}}: \mathrm{MPa}$ & $E_{s}: \mathrm{GPa}$ & $f_{\text {su }}: \mathrm{MPa}$ \\
\hline I & 37.5 & $29 \cdot 7$ & $2 \cdot 30$ & $64 \cdot 3$ & $29 \cdot 4$ & 510 & 200 & 610 \\
\hline$\|$ & 34.5 & 27.7 & $2 \cdot 20$ & $61 \cdot 2$ & 28.7 & & & \\
\hline
\end{tabular}

* Calculated based on Eurocode 2

Table 2. Material properties of the concrete and reinforcing steel

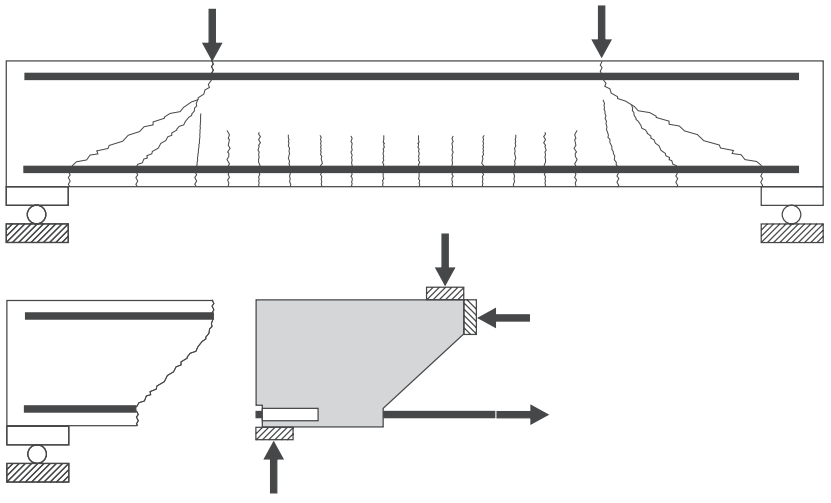

Figure 1. Schematic illustration of the eccentric pull-out specimen

of $20 \mathrm{~mm}$ in the horizontal position at the bottom of the moulds, and with a transverse reinforcement of $8 \mathrm{~mm}$. A small concrete cover to the main bar, 1.5 times the main bar diameter, was used. The main bars were in contact with the concrete over a $210 \mathrm{~mm}$ embedment length; the bond-free zone over the support reduced the direct effect of support pressure. Two types of specimen were prepared, with and without stirrups over the embedment length; see Figure 2. All the specimens had two stirrups outside the embedment length: one at the support and the other in the 'nose', to avoid shear failure of the test specimens.

\section{Electrochemical corrosion}

Specimens were corroded by an electrochemical method using impressed current. During the corrosion process, the specimens were placed upside down, with the main bars near the top; see Figure 3. The current flowed through the main bars across the top concrete cover to a cathode placed at the top of the beam, inside a tank containing a solution of $3 \%$ chloride. Thus, the corrosion attack took place from one direction. Stirrups in the type B specimens were insulated using polyvinyl chloride (PVC) electrical tape to prevent corrosion. The current density was low, with an average value of $100 \mu \mathrm{A} / \mathrm{cm}^{2}$. Specimens were corroded up to 10 months, reaching approximately $2 \%$ weight loss for each month. When compared with artificial corrosion tests in the literature, this can be considered a low value. Other researchers have used faster rates, by as much as one order of magnitude.
Spurious mechanical concrete-steel bond deterioration has been measured for high current density values (Saifullah and Clark, 1994; Yuan et al., 2007); for a review of the effect of corrosion rate on bond strength, see Sæther (2009) and Sæther et al. (2007). Pull-out tests were carried out on reference specimens and corroded specimens at three levels, see also Table 1:

(a) Level 1 corresponded to cracks occurring along the main reinforcement; at a corrosion level lower than $2 \%$ weight loss in the main bars.

(b) Level 2 corresponded to a corrosion level of $2-10 \%$ weight loss in the main bars.

(c) Level 3 corresponded to extensive cover cracking, at a corrosion level greater than $10 \%$ weight loss in the main bars.

Corrosion attack was determined theoretically using Faraday's law and a posteriori by weight loss measurements. This was done for all specimens except one which was kept for another phase of the research programme. The average difference between the two methods was approximately $10 \%$; the corrosion penetrations were overestimated by Faraday's law. Crack widths on the bottom and side covers were measured during the corrosion process using a microscope with a resolution of $0.04 \mathrm{~mm}$ up to corrosion level 1 . Beyond that level of corrosion, most cracks were filled by corrosion products to a point that the optic device could no longer be used. Crack widths at levels 2 and 3 were measured before the load testing using a reference ruler with a range of graded lines, each corresponding to a specified width.

\section{Test arrangement and method}

The specimens were tested in a specially designed test rig. The test set-up is outlined in Figure 4. Deformation control was adopted to permit measurements of the post-peak behaviour. The loading was controlled by displacement, with the active end of the main bar being pulled out. The deformation rate was initially about $0.10 \mathrm{~mm} / \mathrm{min}$; after the maximum load capacity was reached, the deformation rate was increased in steps to a maximum rate of about $0.50 \mathrm{~mm} / \mathrm{min}$. In each test either the middle bar or the two corner bars of the specimen were pulled out.

The tensile force in the bars was measured using load cells. Instrumentation was provided to measure the relative displace- 

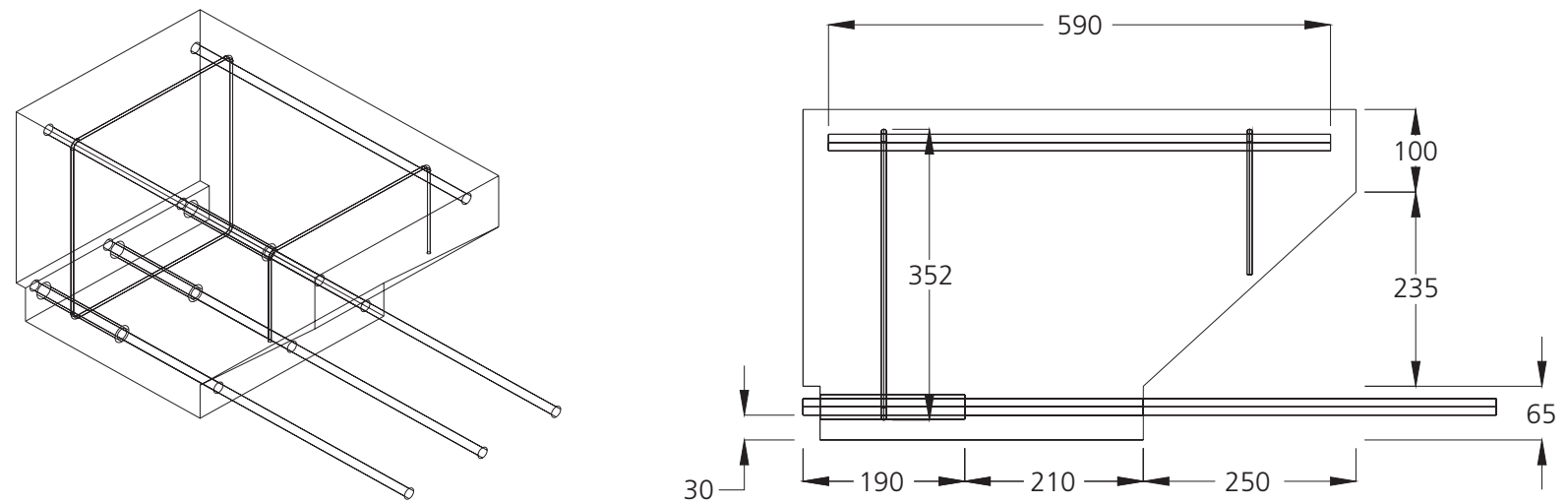

(a)
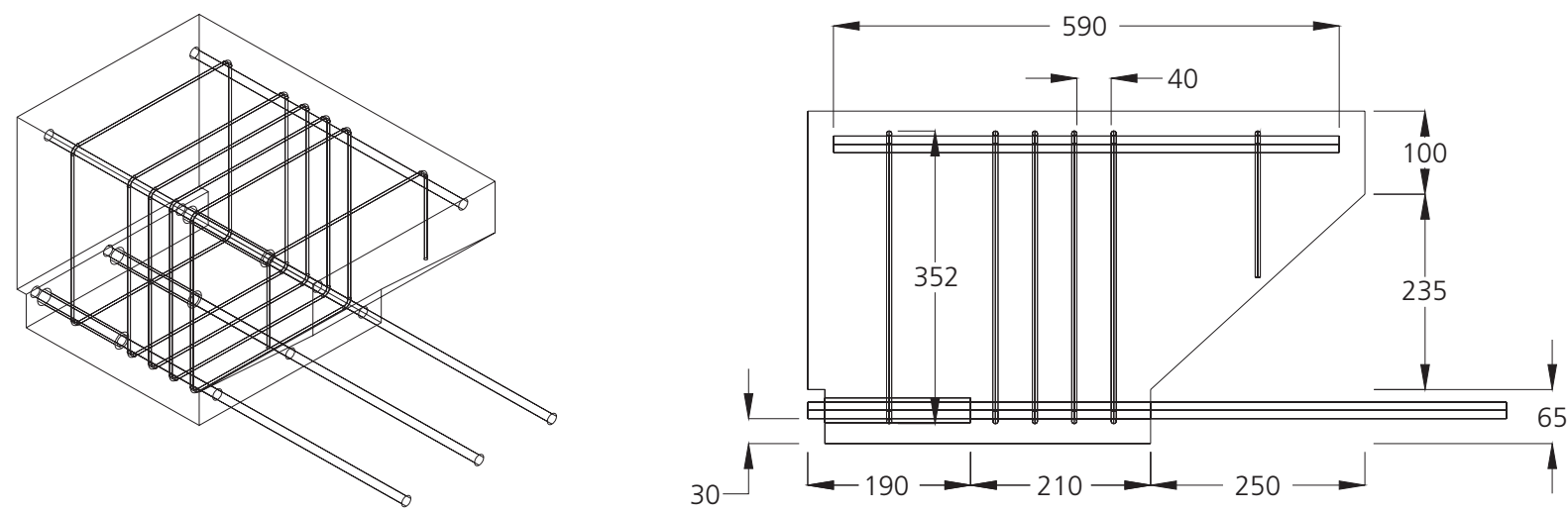

(b)

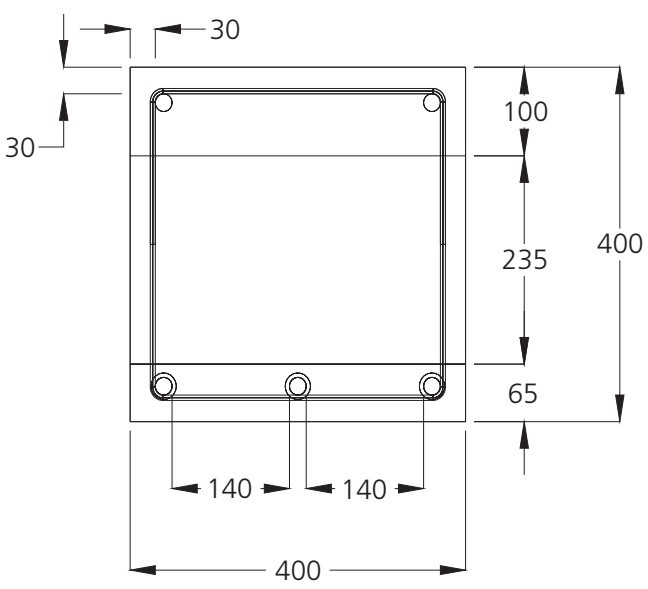

(c)

Figure 2. Specimen geometry and reinforcement: (a) specimen types $A$; (b) specimens types B and C; and (c) cross-section of all the three types of specimen. All dimensions are in $\mathrm{mm}$

ment of the main bars at both the active and passive ends relative to the stable faces of the specimen. When the corner bars were tested, the two bars were loaded simultaneously. Displacement was controlled using two linear variable differ- ential transformers (LVDTs), and the loads were read using two load cells mounted on each individual bar; it was, therefore, possible to register the individual response of each bar. 

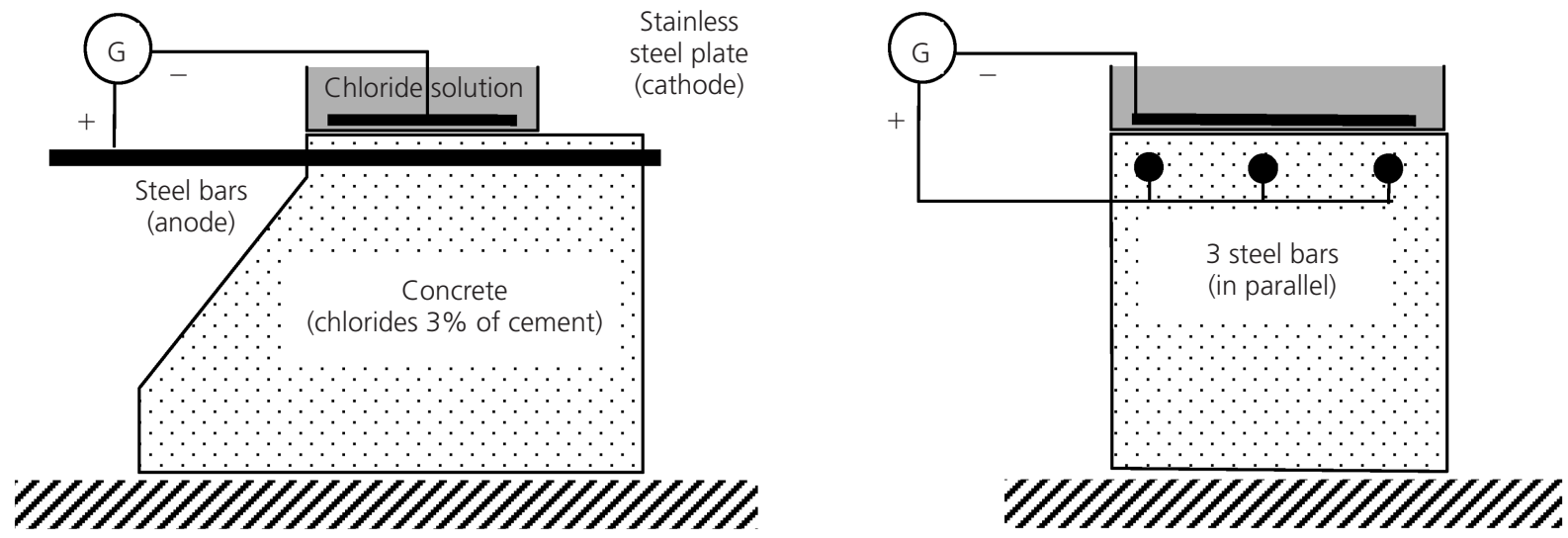

Figure 3. Electrochemical corrosion set-up

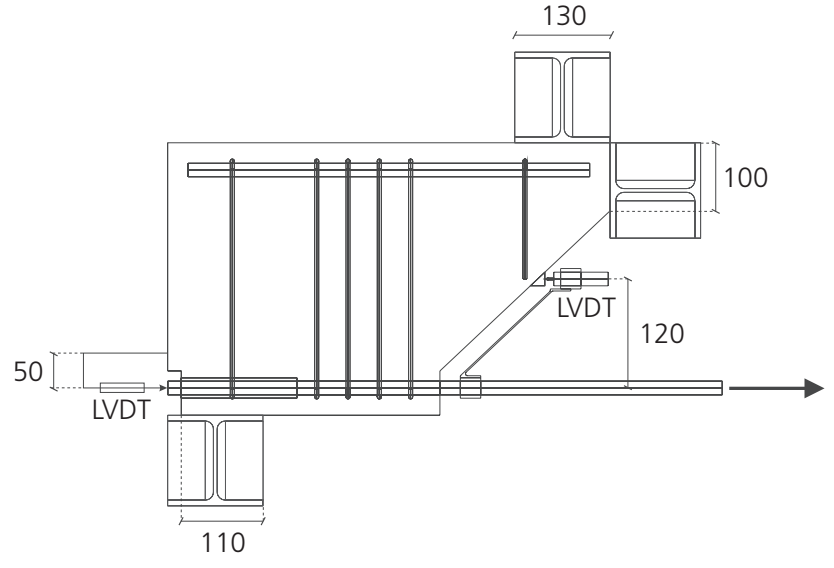

Figure 4. Test set-up and instrumentation; dimensions are in $\mathrm{mm}$

\section{Numerical analysis}

The eccentric pull-out tests were analysed in detail using nonlinear three-dimensional finite-element (FE) models by use of the FE program Diana. The analyses were carried out in two phases. In the first phase, the corrosion attack was applied in time steps as the expansion of the corrosion products. In the second phase, the external load was gradually imposed on the tested bar according to the prescribed displacement. An incremental static analysis was made using a Newton-Raphson iterative scheme to solve the non-linear equilibrium equations.

\section{FE model}

Owing to symmetry, half of the specimen was modelled with an approximate element size of $10 \mathrm{~mm}$, Figure 5. Four-node, threesided isoparametric solid pyramid-shaped elements were used for the concrete, transverse and longitudinal reinforcements. For concrete, a constitutive model based on non-linear fracture mechanics using a smeared rotating crack model based on total strain was applied (Diana, 2009). The crack band width was assumed to be equal to the element size; this was later verified to be a good

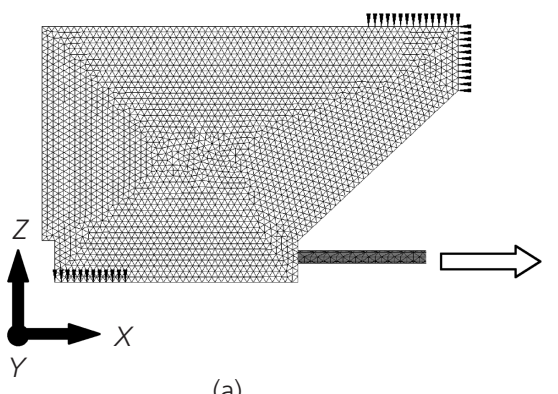

(a)

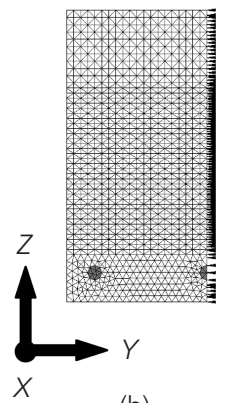

(b)
Figure 5. Finite-element mesh with the boundary conditions at (a) the supports and (b) symmetry plane

approximation of the localisation zone in the analyses. For the concrete in compression and tension, the models by Thorenfeldt et al. (1987) and Hordijk (1991) were adopted, respectively. The reinforcing steel was modelled according to an isotropic plastic model with the Von Mises yield criterion. The material properties used in the analyses are given in Table 2; the compressive strength evaluated from cylinder specimens was used.

As in the experiments, the longitudinal bars were subjected to corrosion attack from one direction, that is, half of the main bar cross-section was affected by corrosion; see Figure 6. The corrosion penetration imposed on half of the main bar crosssection was equivalent to the total bar weight loss measured along the embedment length. The bottom leg of the stirrups was subjected to corrosion all around the cross-section. The vertical leg of the stirrups was corroded halfway up to the longitudinal bar section. These choices corresponded to the experimental observations. In the experiment, the corrosion penetration differed between different bars. In the analyses, however, the same corrosion penetration was imposed on all of the bars; this corrosion level corresponds to the corrosion penetration of the bars tested, shortly before the pull-out test. 


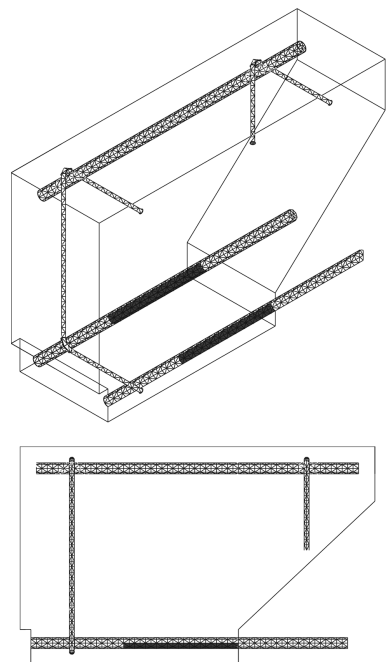

Type A

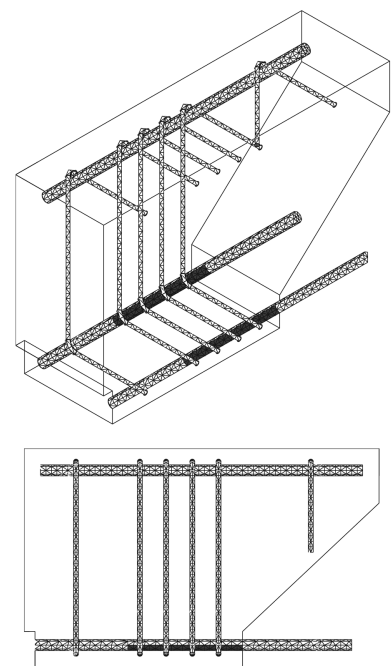

Type B

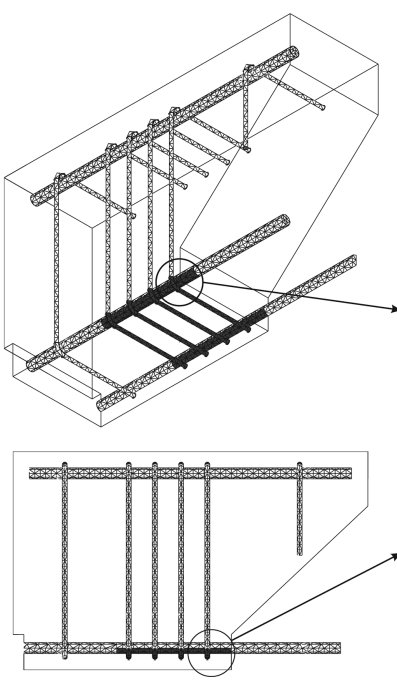

Type C

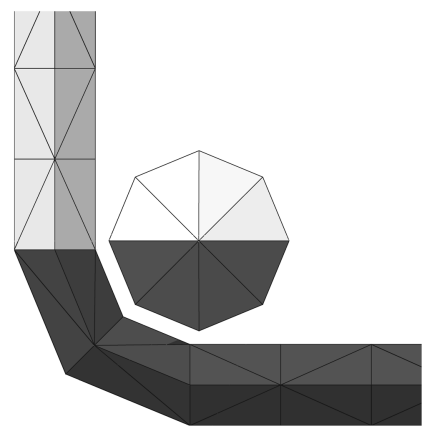

Corrosion illustration

Figure 6. Finite-element model of the eccentric pull-out

specimen; the black parts of the bars and stirrups were subjected

to corrosion

\section{Bond and corrosion models}

In an earlier work, a general model of the bond mechanism was developed (Lundgren and Gylltoft, 2000; Lundgren, 2005a); the model was later combined with the modelling of corrosion in reinforcement (Lundgren, 2002; Lundgren, 2005b). The modelling approach is especially suited for detailed three-dimensional FE analyses, where both the concrete and the reinforcement are modelled with solid elements. Surface interface elements are used at the steel/concrete interaction to describe a relation between the traction, $\sigma$, and the relative displacement, $u$, in the interface. The interface elements include a bond model and a corrosion model, which can be viewed as two separate layers around a reinforcement bar.

The bond model is a frictional model that uses elasto-plastic theory to describe the relations between stresses and deformations. The stresses are limited by two yield functions. One explains the friction, $F_{1}$, assuming that the adhesion is negligible, and the other, $F_{2}$, describes the upper limit at a pull-out failure determined from the stress in the inclined compressive struts that result from the bond action.

1. $F_{1}=\left|\sigma_{\mathrm{t}}\right|+\mu \sigma_{\mathrm{n}}=0$

2. $F_{2}=\sigma_{\mathrm{t}}^{2}+\sigma_{\mathrm{n}}^{2}+c \sigma_{\mathrm{n}}=0$

where $\sigma_{\mathrm{t}}$ and $\sigma_{\mathrm{n}}$ are the bond and splitting stresses, respectively; $\mu$ is the coefficient of friction; and $c$ is the stress in the inclined compressive struts. The maximum bond capacity that can be obtained is roughly half the compressive stress that can be carried in the inclined struts; that is, roughly half the compressive strength of the concrete. When the stresses are limited by the function describing the friction, $F_{1}$, normal stresses are generated. Thus, the model describes the basic mechanisms of bond.

In the corrosion model, the effect of corrosion is simulated as the volume increase of the corrosion products compared with the virgin steel. The volume of the rust relative to the uncorroded steel, $v_{\mathrm{rs}}$, and the corrosion penetration as a function of the time, $x$, is used to calculate the free increase of the bar radius, $y$; that is, the increase in radius including the corrosion products when the normal stresses are zero.

3. $y=-r+\sqrt{r^{2}+\left(v_{\mathrm{rs}}-1\right)\left(2 r x-x^{2}\right)}$

where $r$ is the original bar radius. As the rust is not free to expand, the mechanical behaviour of the rust itself is included. The rust is assumed to have a mechanical behaviour similar to that of a granular material; that is, its stiffness increases with the stress level. The corrosion is then modelled by taking time steps. The corrosion model was shown to be capable of describing the effects of uniform and localised corrosion (Lundgren, 2005b). However, only the effect of uniform corrosion was included in the numerical analysis of the eccentric pull-out test specimens.

The ratio of volumetric expansion of some typical oxides with respect to the virgin material, given in the literature (Liu and Weyers, 1998), varies between 1.7 for $\mathrm{FeO}$ and $6 \cdot 15$ for $\mathrm{Fe}(\mathrm{OH})_{3} 3 \mathrm{H}_{2} \mathrm{O}$. The value of 2.0 (Molina et al., 1993) is 
frequently used in numerical analysis of corroded concrete (Coronelli and Gambarova, 2004; Lundgren, 2003; Lundgren et al., 2007; Zandi Hanjari, 2008); although Bhargava et al. (2006) proposed a value of 3.4 based on the available published experimental data. However, since the corrosion model used in these analyses was calibrated with a value of $2 \cdot 0$ for volumetric expansion of rust, the same value was chosen for all of the analyses presented here.

\section{Results and discussion}

\section{Bond strength}

An overview of the test results in comparison with the indicative reduction in residual bond strength for corroded reinforcement given by Model Code 2010 (Fib, 2010) is presented in Figure 7. The bond strengths of the eccentric pull-out specimens were normalised once with respect to that of the middle bar in

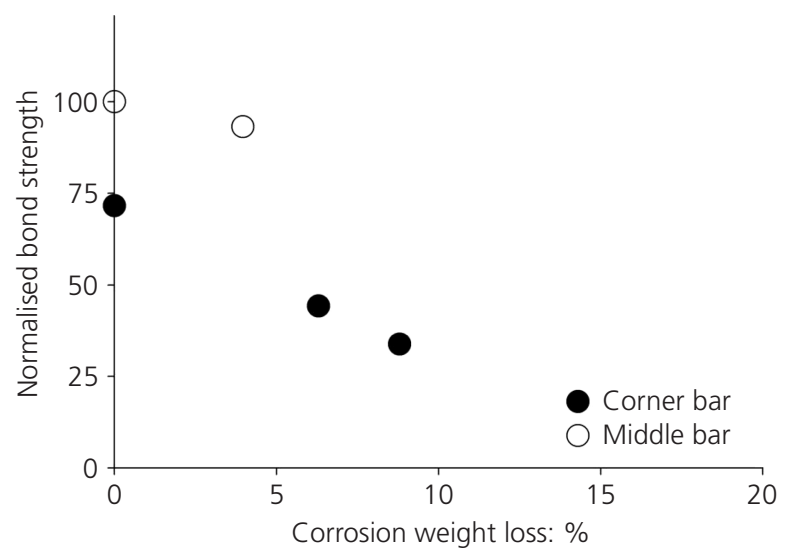

(a)

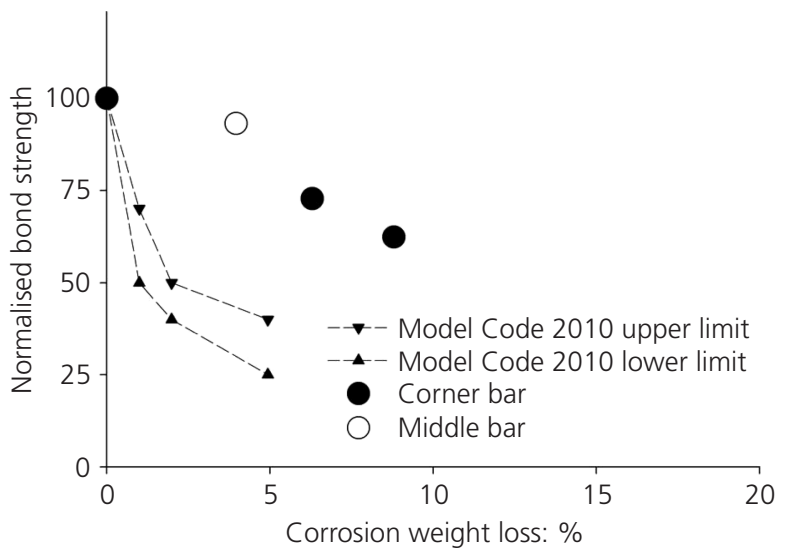

(c)

Figure 7. Overview of the test results in terms of bond strength, (a) and (b) normalised with respect to that of the middle bar in reference specimens; (c) and (d) normalised with respect to that of the reference specimens, plotted against corrosion attack: (a) and (c) specimens without stirrups; (b) and (d) specimens with stirrups reference specimens (a) and (b), and with respect to that of the reference specimens (c) and (d); this was done separately for the specimens with and without stirrups.

In general, the average bond strength of specimens with stirrups was less influenced by corrosion compared to that of the specimens without stirrups. This shows the importance of the confinement provided by stirrups after cover cracking. In the reference specimens without stirrups, the corner bars showed about a $25 \%$ lower bond strength than the middle bars; a larger difference, over $50 \%$, in bond strength of the corner and middle bars was seen in the corroded specimens. A small effect of the bar position was seen in the presence of stirrups, both in reference and corroded specimens. The large bond deterioration seen in the corroded specimens without stirrups agrees well with what has been observed in pull-out tests by other researchers (Almusallam et al., 1996; Fang et al., 2004; Lee et al., 2002); a reduction of

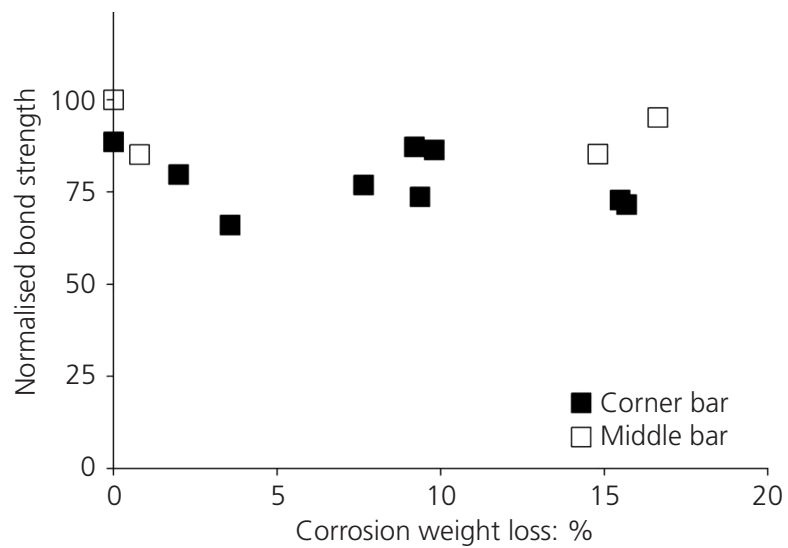

(b)

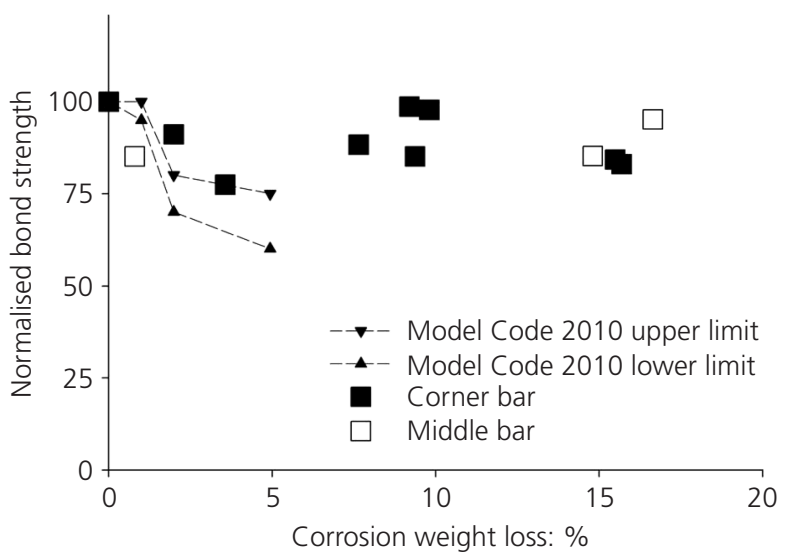

(d) 
about $50 \%$ in bond strength for a corrosion level of about $5 \%$ weight loss has been reported.

As can be seen in Figure 7(b), there was a relatively large bond deterioration in specimens with stirrups for small corrosion attacks, up to about $5 \%$ weight loss. No significant bond deterioration was observed for larger corrosion attacks. An explanation can be that the pressure around the bar suddenly decreased in specimens with small corrosion penetration when the concrete cover cracked. However, for larger corrosion penetrations, the cracks were filled with rust and resulted in an increased pressure around the bar. Therefore, when a pull-out load was applied, it was not only the stirrups that provided confinement; the pressure around the bar owing to accumulated rust also contributed to a higher bond capacity. Similar behaviour has been seen in pull-out tests carried out on specimens with stirrups (Fang et al., 2004). These authors measured no substantial bond reduction in specimens corroded up to a $6 \%$ weight loss.

Comparison of the test results with the predictions given by Model Code 2010 shows that the reductions in bond strength indicated by Model Code 2010 were primarily on the safe side. However, the predictions did not include the effect of the position of the anchored bar. These experimental results indicated a significant influence of the bar position, especially in the absence of stirrups. It should also be noted that, as in many other studies, a large scatter was seen in the pull-out tests of corroded bars.

\section{Failure mode}

Different types of crack patterns at failure were observed depending of the level of corrosion and presence or absence of stirrups; see Figure 8: (a) Failure of the test specimen: inclined cracks starting from the bottom support towards the top supports; this occurred in only one specimen of type B with small corrosion penetration.

(b) Splitting-induced pull-out failure: cracks running along the bar and turning parallel to the inclined side of the 'nose'; this developed mostly in non-corroded specimens.

(c) Splitting failure: splitting cracks parallel to the bar, mainly in corroded specimens.

The three types of failure modes were also seen in the numerical analysis; this was in good agreement with the experiments; see Figure 8. Splitting-induced pull-out failure, which occurred in most of the reference specimens, was further studied in the analyses. The variation in the bond stress along the embedment length seen in the analysis of a corner bar in a reference specimen of type B is shown in Figure 9. It was found that several local bond failures took place along the embedment length, starting from the loaded end of the bar for a small imposed displacement of about $0.35 \mathrm{~mm}$. With increased displacement, bond failures progressively extended along the embedment length towards the free end of the bar. Bond stresses suddenly decreased with the development of each inclined crack. Owing to progressive local bond failures and extensive concrete cracking, the global failure of the anchored bar was characterised as splitting-induced pull-out failure. Figure 9 also shows the influence of the support pressure on the bond stresses close to the support region; even if this effect was reduced by the bond-free zone over the support, it appeared from the analyses to be rather substantial. It should be noted that neither in the tests nor in the numerical modelling did the longitudinal reinforcement yield. As far as numerical results are concerned, no yielding of the stirrups
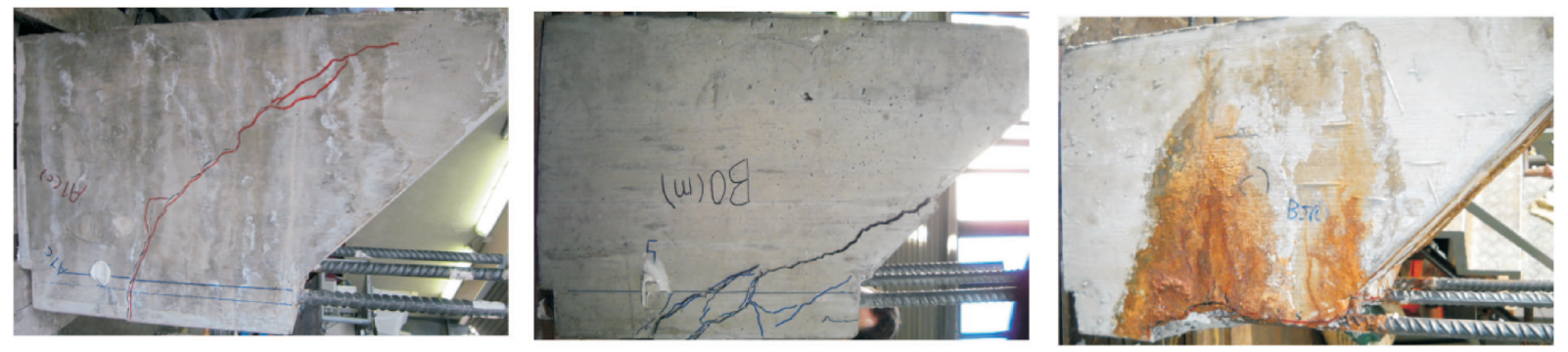

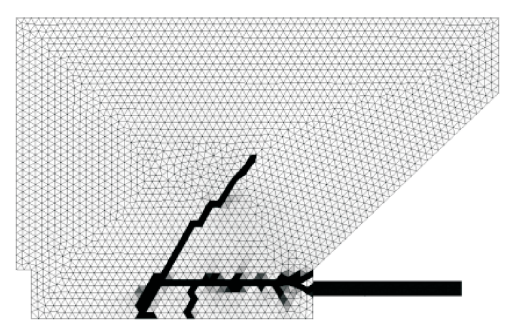

(a)

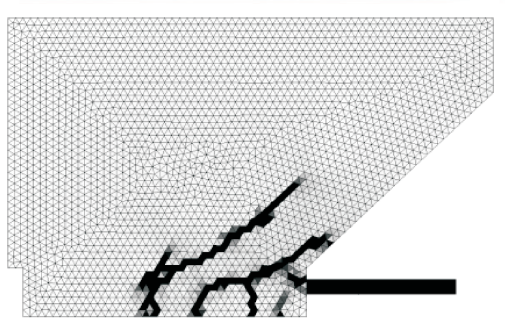

(b)

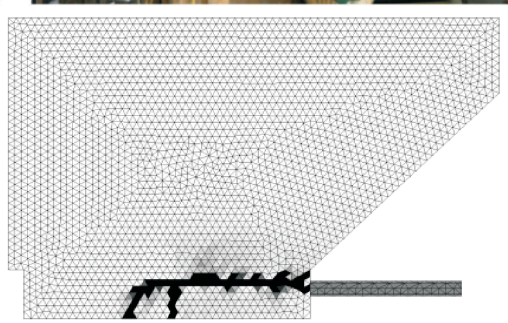

(c)

Figure 8. Crack patterns at different failure modes observed in tests and numerical analyses: (a) failure of the test specimen, (b) splitting-induced pull-out failure and (c) splitting failure 

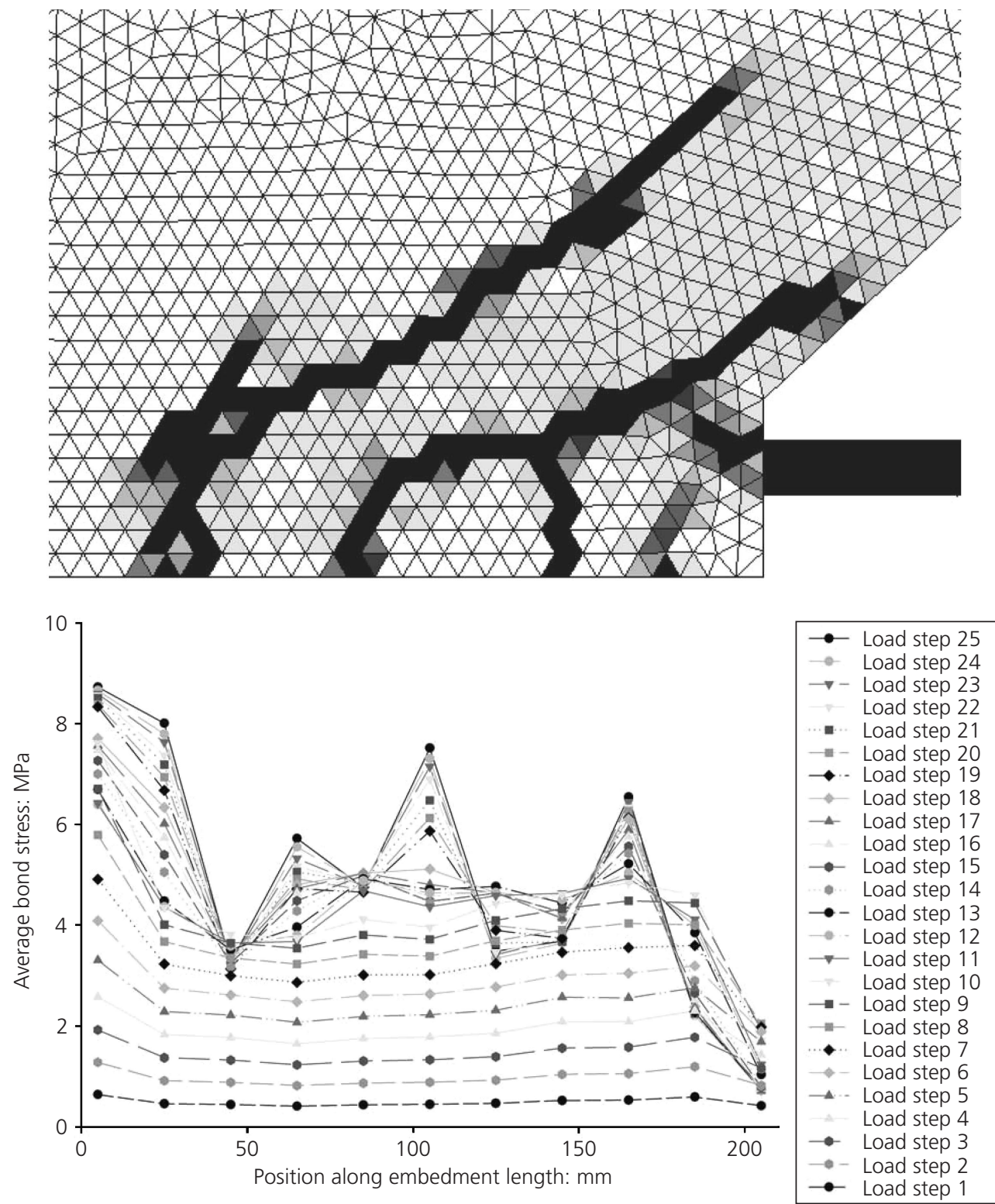

Figure 9. Variation of the bond stress along the embedment length in the analysis of a pull-out test on a corner bar in a reference specimen of type $B$; each load step is equal to an $0.05 \mathrm{~mm}$ displacement imposed on the active side of the corner bar

took place; $350 \mathrm{MPa}$ was the maximum stress in the stirrups observed in the analyses.

\section{Bond stress plotted against slip}

The load measured on each bar was divided by the surface area of the bar along the embedment length to calculate the average bond stress; this was plotted against the slip at the free end; see Figure 10. The results given for the reference specimens are averages of at least two specimens; see Table 1. The numerical results in terms of bond stress plotted against slip are compared with those of the tests in Figure 11.

The numerical analyses showed good correspondence with the tests results, confirming the failure modes and crack pattern seen in the tests; see Figure 12. The analyses also gave reasonably good results in terms of bond stress plotted against slip for the specimens with small corrosion attacks, up to about $1 \%$. One small difference between tests and analyses concerns the slip for 


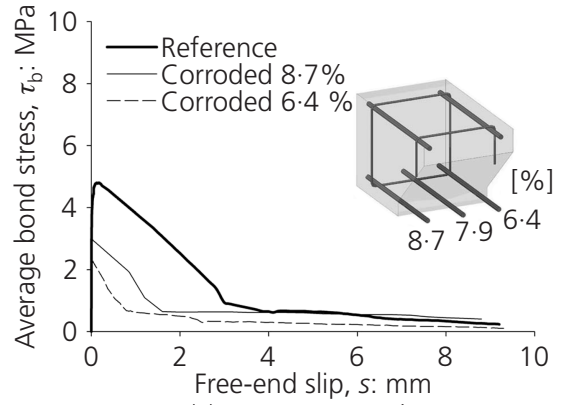

(a) type A-corner bar

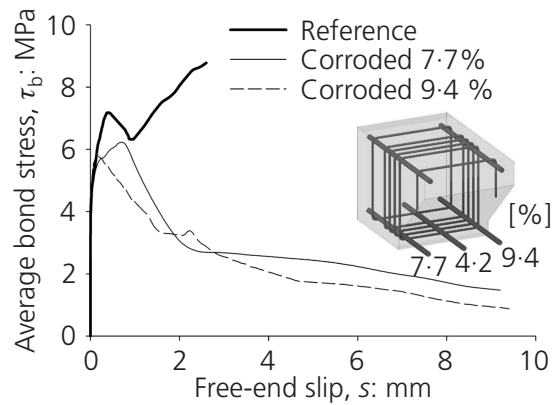

(d) type B-corner bar

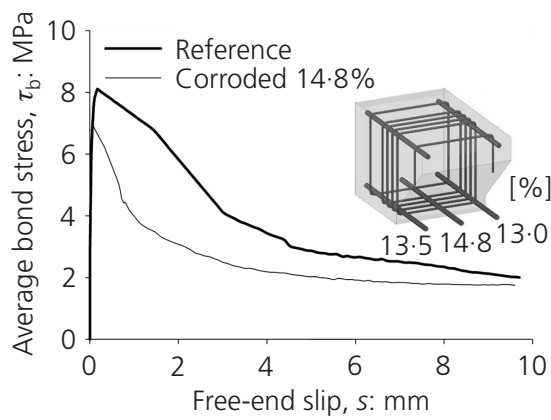

(g) type B-middle bar

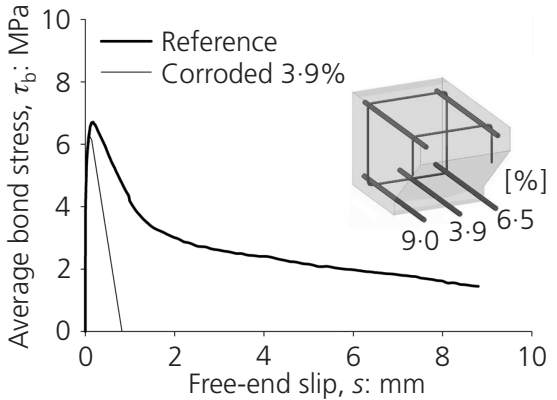

(b) type A-middle bar

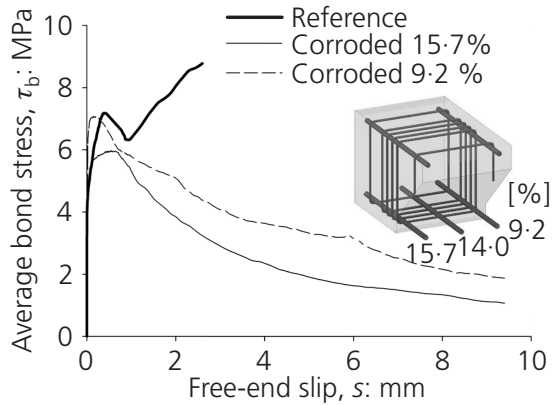

(e) type B-corner bar

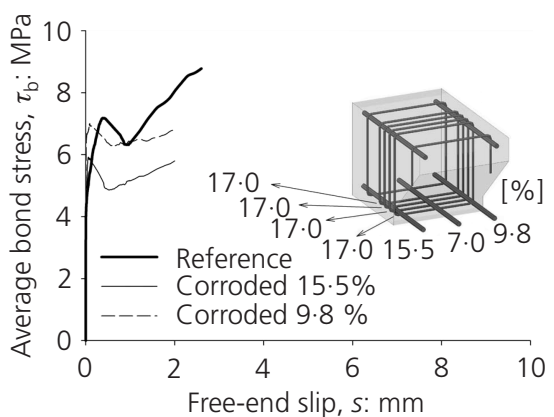

(h) type C-corner bar

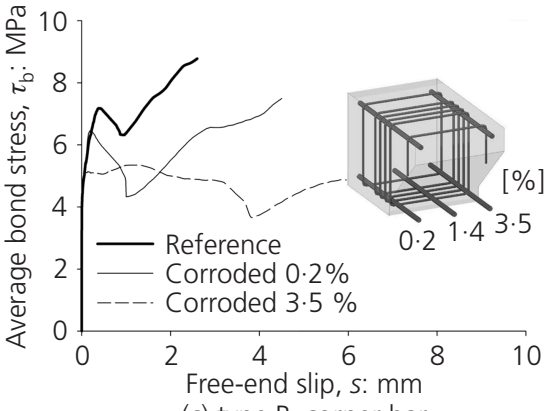

(c) type B-corner bar

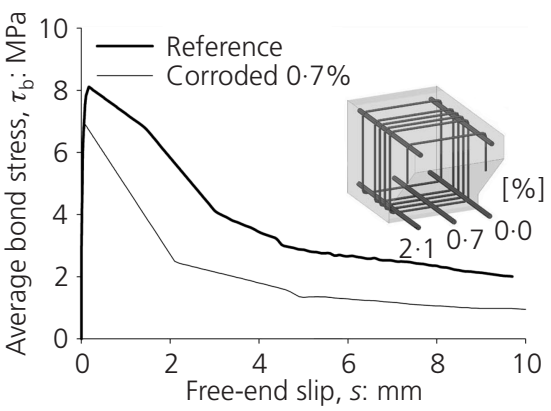

(f) type B-middle bar

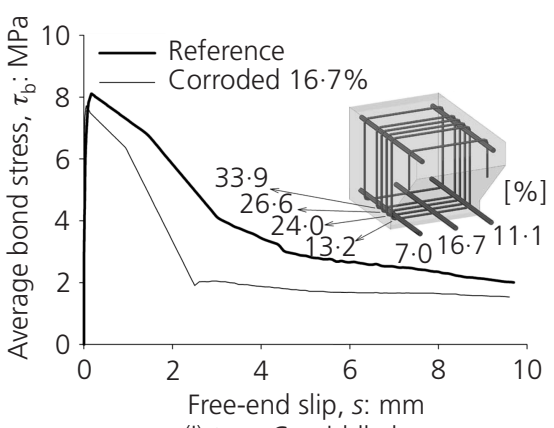

(i) type C-middle bar

Figure 10. Average bond stress versus free-end slip measured in the pull-out tests. The numbers in the figures indicate the corrosion weight loss measured on each bar except in (h) type $C$ - corner bar, where the corrosion weight loss was estimated from the impressed current using Faraday's law: (a) type A corner bar; (b) type A - middle bar; (c) type B - corner bar; (d) type B - corner bar; (e) type B - corner bar; ( $f$ ) type B middle bar; ( $g$ ) type $B$ - middle bar; ( $h$ ) type $C$ - corner bar; (i) type $\mathrm{C}$ - middle bar

the non-corroded specimens; as can be seen in Figure 11 the analyses result in weaker behaviour with slightly larger slip values for the ascending branch than the test results. This behaviour can be seen also in earlier analyses with the used bond model (Lundgren, 2005a; Lundgren, 2005b). The main reason for this difference is that the main focus when the bond model was calibrated was the ultimate limit state, with anchorage failure. Thus, to change this, the bond model needs to be better calibrated for small slip values.
Further, it should be noted that for corrosion attacks larger than about $1 \%$, the deterioration observed in the analysis was considerably greater than that in the tests. The analyses could thus not be carried out for large corrosion penetrations, as the damage level resulted in extensive cover cracking and made the analysis numerically unstable. The maximum corrosion levels achieved in the analyses were $1.4 \%, 1.7 \%$ and $0.3 \%$ for specimens of types $\mathrm{A}, \mathrm{B}$ and $\mathrm{C}$, respectively. Thus, the second phase of the analyses simulating the pull-out tests was carried 


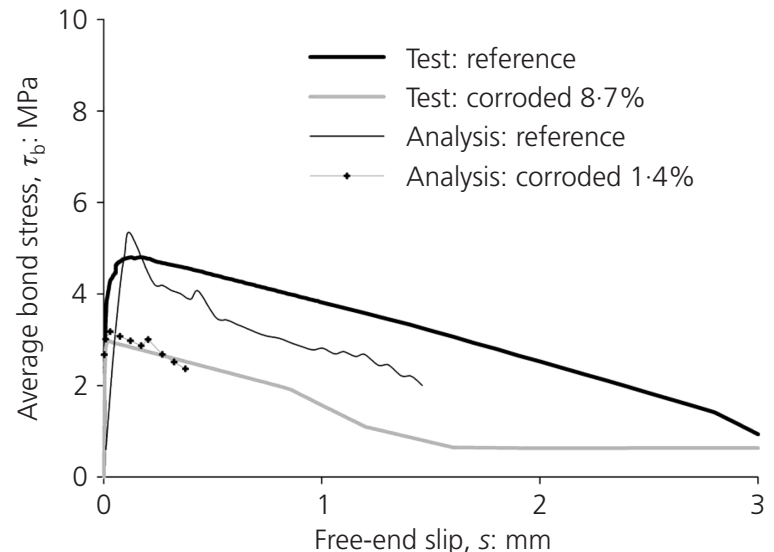

(a) type A-corner bar

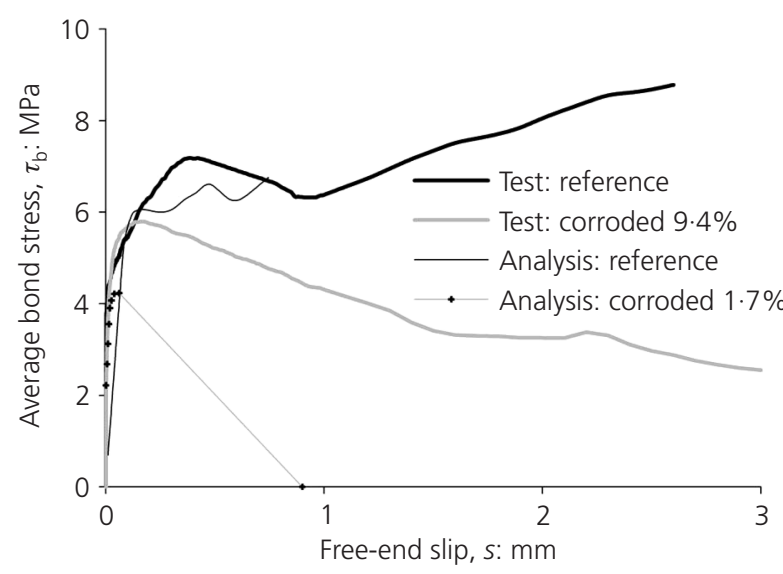

(c) type B-corner bar

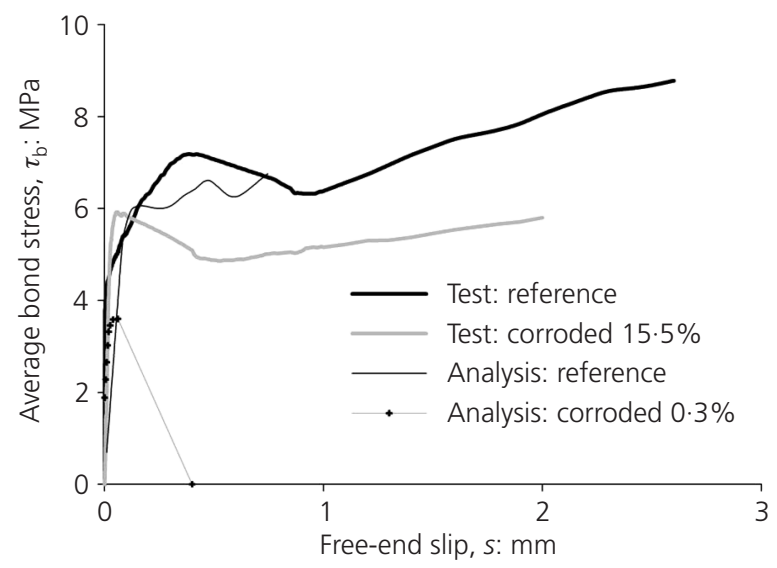

(e) type C-corner bar

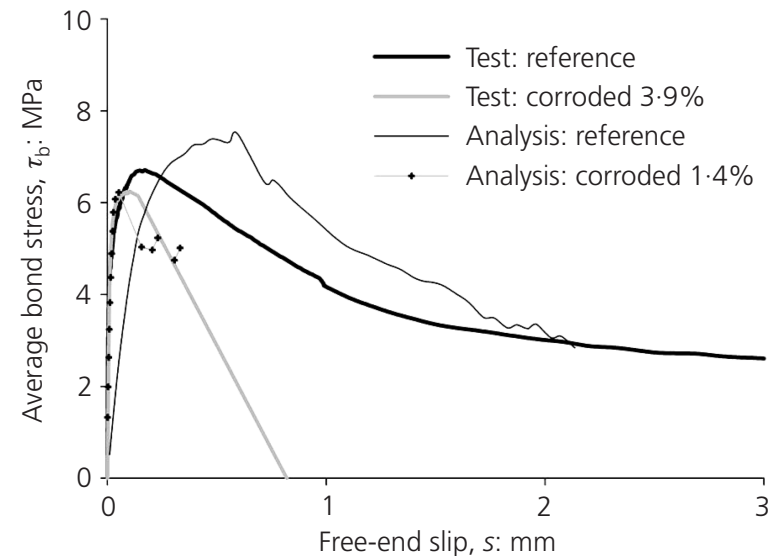

(b) type A-middle bar

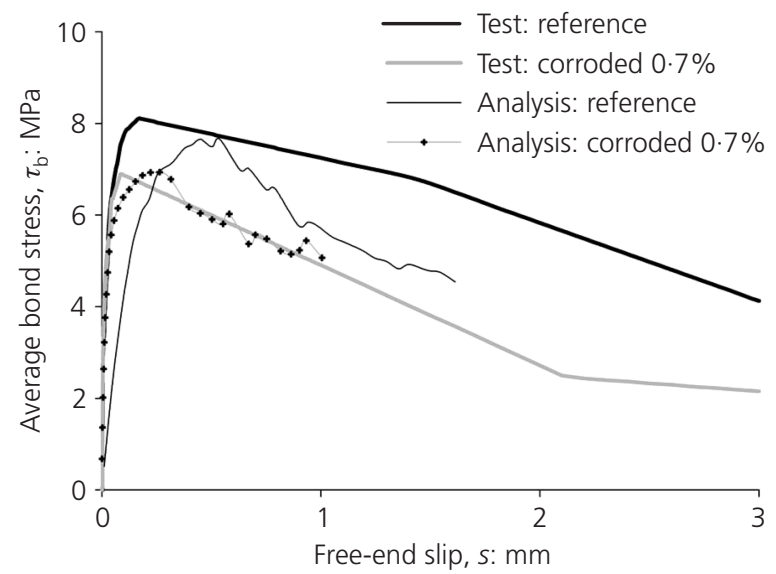

(d) type B-middle bar

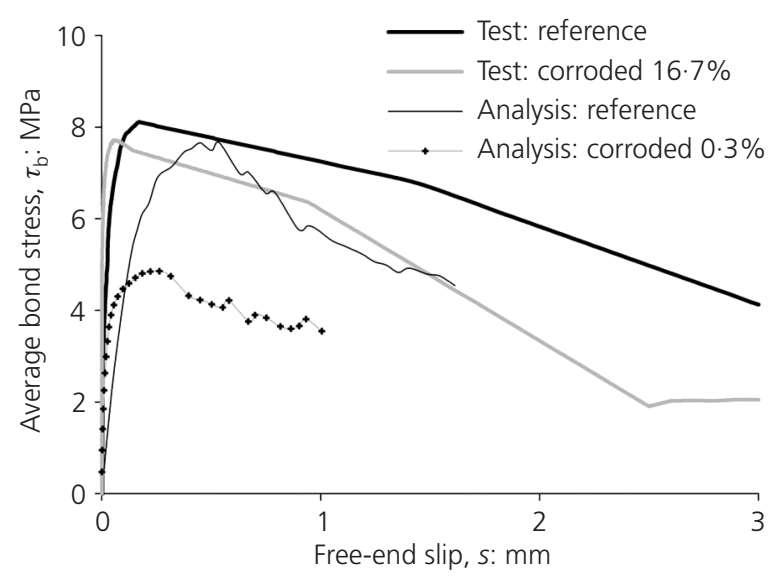

(f) type C-middle bar

Figure 11. Average bond stress plotted against free-end slip from numerical analysis and experiments: (a) type $\mathrm{A}$ - corner bar; (b) type A - middle bar; (c) type B - corner bar; (d) type B middle bar; (e) type $C$ - corner bar; (f) type $C$ - middle bar

out with these corrosion attacks; see Figure 11. The difference in the corrosion levels that caused extensive cover cracking and termination of the analysis for the three types of specimen was related to the amount of confinement; that is, the presence or absence of stirrups and whether or not the stirrups were corroded.

The inconsistency observed between numerical analyses and tests 

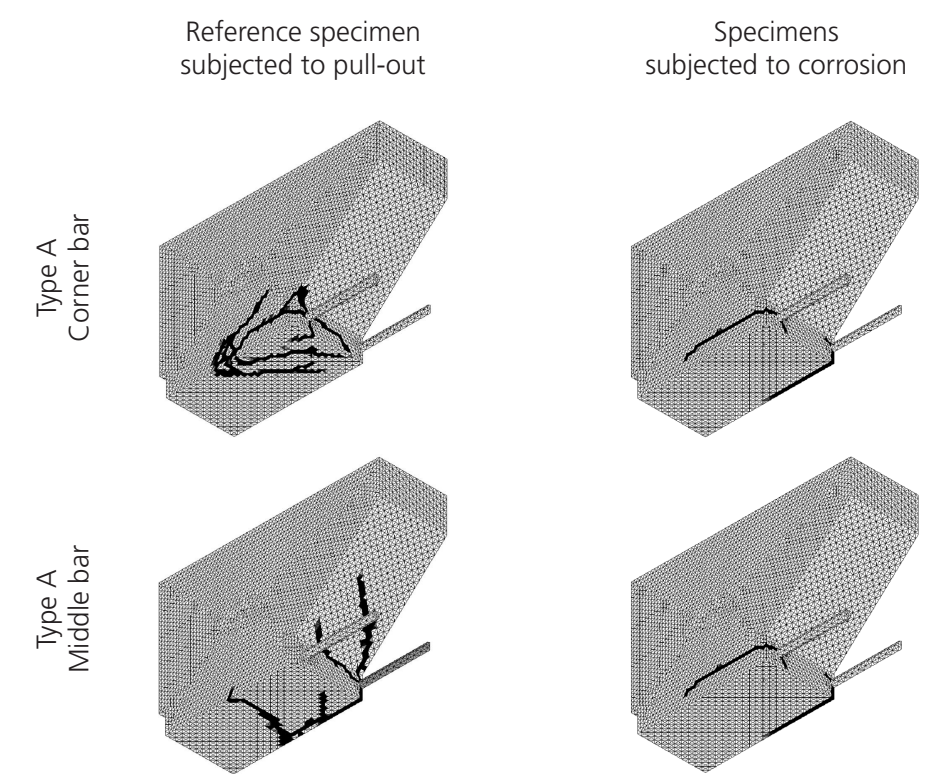

Corroded specimens subjected to pull-out test
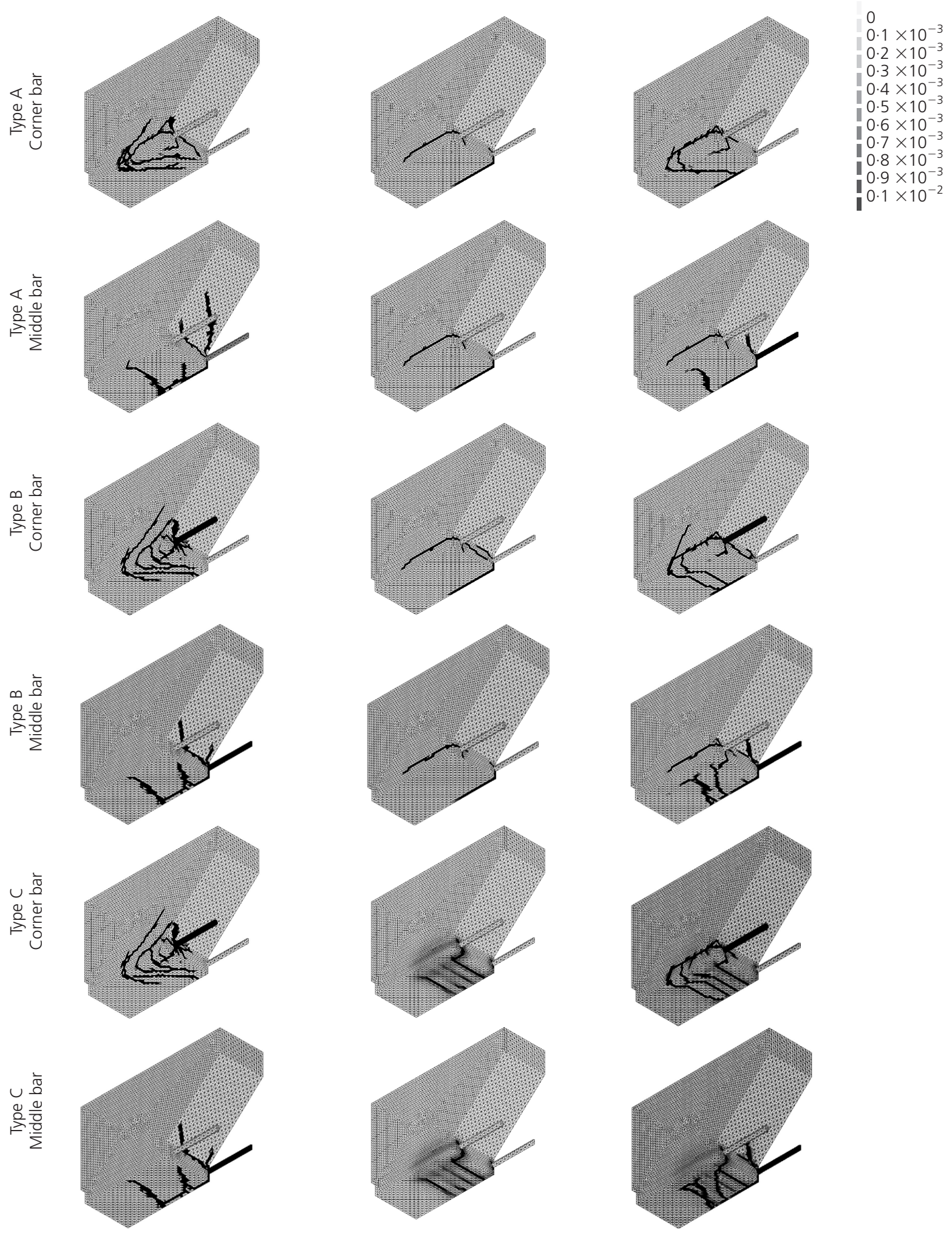

Figure 12. Crack pattern in terms of the maximum tensile strains from numerical analysis of the eccentric pull-out tests 
for high corrosion penetrations can be explained by the tendency of the corrosion products to penetrate into cracks and reach the external surface of the cover (Berra et al., 2003). This may significantly decrease the pressure around the corroded bars and consequently reduce the damage to the surrounding concrete. Slow corrosion rates, as in this study, provide sufficient time for rust penetration effectively to take place. This has been seen in real structures exposed to natural corrosive environments. Extensive rust flowing through the corrosion cracks into the electrolyte (chloride solution) was observed in the current experimental study as well as in several other experimental works. The corrosion model used in the numerical analysis does not include this phenomenon. Thus further research developments are needed for numerical modelling of high corrosion levels.

A comparison of the results of specimen types A, B and C shows the importance of the stirrups in the remaining bond capacity of corroded specimens. The largest bond deterioration was seen in the type A specimens on the corner bars; this was because of the absence of stirrups as well as less portion of surrounding concrete available to a corner bar compared to that of a middle bar. The least bond deterioration was measured in type B specimens on the corner bars. This is believed to be caused by the effective interaction between the stirrups and the main bars at the angle of the corner. It can be concluded that, for large corrosion penetrations that cause extensive cover cracking, stirrups play an important role in terms of being the main source of confinement. The following discusses the experimental and numerical results for each specimen type.

\section{Specimens type A: without stirrups}

The bond strength of corner bars was considerably lower than that of the middle bars in the specimens without stirrups, Figure 10(a) and (b); this was seen in both reference and corroded specimens. The pull-out tests on corner bars showed a roughly $50 \%$ reduction in bond strength caused by $8.7 \%$ corrosion. While less bond deterioration was observed in the pull-out tests on the middle bar, the failure was more brittle.

The cracking in reference specimens started with the development of a dominant longitudinal crack that appeared on both the bottom and side covers along the embedment length. This was followed by extensive inclined cracking that formed a splittinginduced pull-out failure. Corrosion in these specimens, prior to mechanical loading, led to a wide longitudinal crack along the embedment length. The crack appeared on both the bottom and side covers around a corroded bar in the corner region. This resembles a corner cover spalling situation; although the corner cover had not completely fallen off, as the amount of corrosion was relatively low. The longitudinal corrosion cracks were further opened while the bar was pulled out; no indications of inclined cracking were seen. The bond capacity was limited by spalling of the bottom cover that led to splitting failure. The failure was relatively brittle as no stirrups were present to provide confinement after cover spalling.
The failure modes and crack patterns agreed reasonably well with what was seen in the numerical analysis; see Figure 12. The crack pattern caused in pull-out tests of reference specimens showed a relatively local damage in the concrete around the bar. This means that the cracks originating from the tested bar did not reach the adjacent bar. However, in the pull-out tests of corroded specimens, the cracks initiating from the tested bar propagated towards the weaker zone at the adjacent corroded bars. The average bond strength of middle and corner bars in the reference and corroded specimens was relatively well estimated in the numerical analyses; see Figures 11(a) and (b). However, the maximum corrosion attack achieved in the numerical analyses was $1.4 \%$; this was notably lower than that measured in the specimens.

In two other studies, pull-out tests were carried out in specimens similar to the ones used in the present study (Almusallam et al., 1996; Clark and Saifullah, 1993). The specimens had a prism shape and were cast without stirrups, with four bars arranged at the corners. In the study by Almusallam et al. (1996), a very high corrosion rate of about $3500 \mu \mathrm{A} / \mathrm{cm}^{2}$ was used in artificial corrosion of the bars. Significant bond deteriorations of over $80 \%$ have been reported for corrosion levels greater than $6 \%$. The bond deterioration measured in the other study by Clark and Saifullah (1993), in which a corrosion rate of $500 \mu \mathrm{A} / \mathrm{cm}^{2}$ was adopted, compares well with the results of the current study. A bond loss of about $50 \%$ has been reported for a corrosion level of around $10 \%$ bar. It has also been observed that the corrosion level required to cause cover cracking increased for larger cover; however, the bond strength remained almost unaffected by variation of cover thickness.

\section{Specimens type B: with stirrups}

For the specimens with stirrups, the mechanism that limited the bond of corner bars was different from that observed in the middle bars of reference specimens; this can be seen in a comparison of Figures $10(\mathrm{c}-\mathrm{e})$ and $(\mathrm{f}-\mathrm{g})$. There appeared to be a comparatively large increase in the pull-out force after the first peak in the corner bar tests. The cracking started in these specimens with the development of a transverse crack at the end of the embedment length. At a higher load, this crack propagated further and formed an inclined crack; this corresponds to the first peak. Greater pull-out forces were measured as the stirrups started to function effectively. This was combined with the initiation of several transverse cracks inclining toward the loaded end, forming a splitting-induced pull-out failure that corresponds to the final failure of the specimens. Meanwhile, longitudinal cracks, initiated from the loaded end, stopped when they reached the first stirrup.

The behaviour seen in the pull-out tests of corner bars is believed to be caused by the effective interaction between the main bars and the stirrups at the corner. A visual observation of the tests specimens after the pull-out tests showed a relatively large displacement of the stirrups at the corners; see Figure 13(a). This 


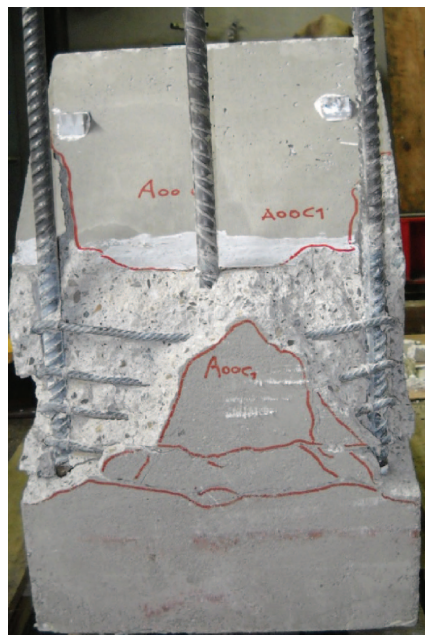

(a)

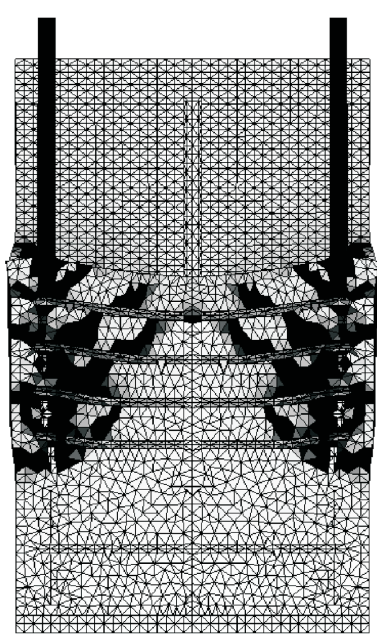

(b)
Figure 13. Crack pattern after pull-out test of corner bars in a reference specimen type $B$ : (a) from experiment, and (b) from numerical analysis

was also observed in the numerical analysis; see Figure 13(b). It should be noted that the interaction between the stirrups and main bars was not geometrically modelled in detail, meaning that the direct interaction was avoided using concrete elements with a size of $2 \mathrm{~mm}$. However, large stresses that developed at the corners between the stirrups and main bars caused a similar effect in the numerical analyses.

The pull-out tests of corner bars in corroded specimens showed relatively low bond deterioration and a different crack pattern at failure in comparison with the reference specimens. The failure of the corroded specimens was governed by spalling of the bottom cover; this formed a typical splitting crack pattern. A strong interaction between the adjacent bars was also seen in specimen type B. Thus, the corrosion-induced cracks reached the adjacent bars and facilitated spalling of the bottom cover in the pull-out tests.

\section{Specimens type C: with corroded stirrups}

In the specimens of type $\mathrm{C}$, more extensive cracking, including several transverse cracks originating from corroded stirrups, was observed in both the tests and numerical analyses, Figure 12. The damage levels reached in corroded specimens did not show full delamination of the cover, although delamination cracks had started and propagated. To the authors' knowledge, no available experimental laboratory study shows full delamination damage. The stirrups were highly corroded in the type C specimens; however, more than half of the cross-section of the stirrups was still present.

The pull-out tests on specimens with corroded stirrups showed a comparatively low bond deterioration. It could be concluded that significant bond deterioration will start only when the level of stirrup corrosion is very high, for example more than 50\%, approaching situations in which some stirrup legs are broken at some points of pitting and/or are nearly consumed by uniform corrosion. Regan and Kennedy Reid (2004) simulated a similar condition in the laboratory, in which beams were cast with shear reinforcement lacking the corner anchorages. A relatively large reduction in the capacity of the beams was observed, in spite of the fact that the effect of cover spalling as a result of stirrups corrosion was not taken into account (Regan and Kennedy Reid, 2004). The level of stirrups and main bar corrosion measured in the specimens of the current study could correspond to the level of damage when the cover is delaminated. This is observed in real structures, but has not yet been reproduced in the laboratory.

The experimental work carried out by Higgins and Farrow III (2006) studied shear capacity of beams with corroded stirrups. A high corrosion rate of $600 \mu \mathrm{A} / \mathrm{cm}^{2}$ was used to produce corrosion in stirrups; corrosion of the flexural reinforcement was prevented. They observed extensive cracking, partial delamination and staining at stirrups' sectional loss of $12 \%, 20 \%$ and $40 \%$. They concluded that visual inspection of corrosion damage did not help to distinguish between the three corrosion levels. Considering the low corrosion rate used in the current study and the comparatively little damage seen in the specimens with corroded stirrups, it is concluded that the corrosion rate of stirrups affects the test results in the same way as the corrosion rate of the main bars. That is, the time to reach a corrosion level is considerably shortened with a high corrosion rate; thus, the flow of rust through cracks does not effectively take place. This is an important phenomenon that ought to be taken into account in experiments and numerical analyses dealing with high corrosion attacks.

\section{Conclusions}

The effect of extensive corrosion of main bars and stirrups on the behaviour of anchored bars at corner and middle positions was investigated. Based on experimental observations and numerical analyses the following conclusions are drawn.

(a) The test results showed the significant influence of the stirrups, the position of the tested bar and the corrosion on the bond capacity and the failure mode.

(b) Less bond capacity was observed for a bar positioned in a corner, which implies that the average confinement available for such a bar is less than that of a middle bar. The difference in the bond capacity, originating from the bar position, became even more important in the absence of stirrups.

(c) When the main bars were corroded, the highest anchorage capacity was measured for a middle bar in the presence of uncorroded stirrups, while the lowest capacity was measured for a corner bar in the absence of stirrups.

(d) A rather complex failure mode was observed in specimens with stirrups. This was a result of the effective interaction between stirrups and main bars at the angle of the corner. In 
the absence of stirrups, the failure of the corroded specimens was mainly governed by splitting of the concrete cover.

(e) The damage levels reached in corroded specimens did not show a full delamination of the cover, although delamination cracks had initiated and propagated. To the authors' knowledge, no experimental laboratory study with artificial corrosion has yet shown full delamination with this stage of damage.

( $f$ ) The deterioration trend proposed by the Model Code 2010, compared to the test results presented in this paper, was conservative.

(g) The numerical analyses showed good correspondence with the test results in reference and corroded specimens, confirming the failure modes obtained in the tests and the load levels.

(h) For high corrosion attacks at low corrosion rates, the effect of rust flowing through cracks becomes important. Further research efforts are therefore needed to make the numerical modelling capable of describing that.

\section{REFERENCES}

Almusallam AA, Al-Gahtani AS and Aziz AR (1996) Effect of reinforcement corrosion on bond strength. Construction and Building Materials 10(2): 123-129.

Azad AK, Ahmad S and Azher SA (2007) Residual strength of corrosion-damaged reinforced concrete beams. ACI Materials Journal 104(1): 40-47.

Berra M, Castellani A, Coronelli D, Zanni S and Zhang G (2003) Steel-concrete bond deterioration due to corrosion: Finiteelement analysis for different confinement levels. Magazine of Concrete Research 55(3): 237-247.

Bhargava K, Ghosh AK, Mori Y and Ramanujam S (2006) Model for cover cracking due to rebar corrosion in rc structures. Engineering Structures 28(8): 1093-1109.

Cabrera JG and Ghoddoussi P (1992) The effect of reinforcement corrosion on the strength of the steel/concrete 'bond'. Bond in Concrete, Proceedings of an International Conference, Riga, pp. 10-11-10-24.

Clark LA and Saifullah M (1993) Effect of corrosion on reinforcement bond strength. Proceedings of the 5th International Conference on Structural Faults and Repairs, Edinburgh 3, 113-119. Engineering Technical Press.

Coronelli D and Gambarova P (2004) Structural assessment of corroded reinforced concrete beams: Modeling guidelines. Journal of Structural Engineering 130(8): 1214 1224.

Diana (2009) Diana Finite Element Analysis, User's Manual, Release 9.3. TNO Building and Construction Research, Delft, Netherlands.

Fang C, Lundgren K, Chen L and Zhu C (2004) Corrosion influence on bond in reinforced concrete. Cement and Concrete Research 34(11): 2159-2167.

Fib (Fédération Internationale du Béton) (2000) Bond of Reinforcement in Concrete. Fédération Internationale du Béton, Lausanne. State-of-the-art report, prepared by Task Group Bond Models.

Fib (2010) CEB-FIP Model Code 2010 - First complete draft.
Bulletin 55, Volume 1, Fédération Internationale du Béton, Lausanne.

Higgins C and Farrow III WC (2006) Tests of reinforced concrete beams with corrosion-damaged stirrups. ACI Structural Journal 103(1): 133-141.

Hordijk DA (1991) Local Approach to Fatigue of Concrete. Doctoral thesis, Delft University of Technology, Netherland.

Hussein N-A, Yang Y, Kawai K and Sato R (2002) Time dependent bond behaviour of corroded bars. Proceedings of a Conference on the Bond in Concrete - from Research to Standards, Budapest, Hungary, pages 166-173.

Lee H-S, Noguchi T and Tomosawa F (2002) Evaluation of the bond properties between concrete and reinforcement as a function of the degree of reinforcement corrosion. Cement and Concrete Research 32(8): 1313-1318.

Liu Y and Weyers RE (1998) Modeling the time-to-corrosion cracking in chloride contaminated reinforced concrete structures. ACI Materials Journal 95(6): 675-681.

Lundgren K (2002) Modelling the effect of corrosion on bond in reinforced concrete. Magazine of Concrete Research 54(3): $165-173$.

Lundgren K (2003) Modelling the splitting effects of corrosion in reinforced concrete. Computational Modelling of Concrete Structures, Euro-C Conference, Austria, pp. 491500 .

Lundgren K (2005a) Bond between ribbed bars and concrete. Part 1: Modified model. Magazine of Concrete Research 57(7): 371-382.

Lundgren K (2005b) Bond between ribbed bars and concrete. Part 2: The effect of corrosion. Magazine of Concrete Research 57(7): 383-395.

Lundgren K and Gylltoft K (2000) A model for the bond between concrete and reinforcement. Magazine of Concrete Research 52(1): 53-63.

Lundgren $\mathrm{K}$, Roman ASS, Schlune $\mathrm{H}$, Hanjari Zandi K and Kettil P (2007) Effects on bond of reinforcement corrosion. International RILEM Workshop on Integral Service Life Modeling of Concrete Structures, Guimaraes, Portugal, pp. 231-238.

Magnusson J (2000) Bond and Anchorage of Ribbed Bars in High-strength Concrete. Doctoral thesis, Chalmers University of Technology, Göteborg, Sweden.

Molina FJ, Alonso C and Andrade C (1993) Cover cracking as a function of rebar corrosion. 2. Numerical model. Materials and Structures 26(163): 532-548.

Regan PE and Kennedy Reid IL (2009) Assessment of concrete structures affected by delamination: 1 - effect of bond loss. Studies and Research - Annual Review of Structural Concrete (29): 245-275.

Regan PE and Kennedy Reid IL (2004) Shear strength of RC beams with defective stirrup anchorages. Magazine of Concrete Research 56(3): 159-166.

Sæther I (2009) Bond deterioration of corroded steel bars in concrete. Structure and Infrastructure Engineering, First 
published on 29 July 2009 (iFirst), doi: 10.1080/ 15732470802674836

Sæther I, Antonsen A and Vennesland Ø (2007) Effect of impressed anodic current density applied to accelerated corrosion laboratory results. International RILEM Workshop on Integral Service Life Modeling of Concrete Structures, Guimaraes, Portugal, pp. 307-314.

Saifullah M and Clark LA (1994) Effect of corrosion rate on the bond strength of corroded reinforcement. Proceedings of International Conference: Crrosion and Corrosion Protection of Steel in Concrete, Sheffield 1, 591-602.

Thorenfeldt E, Tomaszewicz A and Jensen JJ (1987) Mechanical properties of high-strength concrete and applications in design. Proceedings of Conference on Utilization of High-Strength Concrete, Stavanger, Norway, pp. 144-159.

Yuan Y, Ji Y and Shah SP (2007) Comparison of two accelerated corrosion techniques for concrete structures. ACI Structural Journal 104(3): 344-347.

Zandi Hanjari K (2008) Load-Carrying Capacity of Damaged Concrete Structures. Licenciate thesis no. 2008:06, Department of Civil and Environmental Engineering, Chalmers University of Technology, Göteborg, Sweden.

Zandi Hanjari K and Coronelli D (2010) Anchorage Capacity of Corroded Reinforcement: Eccenteric Pull-out Tests.

Department of Civil and Environmental Engineering, Chalmers University of Technology, Göteborg, Sweden, Dipartimento di Ingegneria Strutturale, Politecnico di Milano, Milan, Italy. Report No. 2010-06.

Zhang R (2008) Analysis of both Initiation and Propagation Phases of Corrosion in Reinforced Concrete Structures and their Influence on Service Life. Doctoral thesis, Laboratoire Matériaux et Durabilité des Constructions.

\section{WHAT DO YOU THINK?}

To discuss this paper, please submit up to 500 words to the editor at www.editorialmanager.com/macr. Your contribution will be forwarded to the author(s) for a reply and, if considered appropriate by the editorial panel, will be published as a discussion in a future issue of the journal. 